\title{
ULNAR NERVE CONTRIBUTION IN THE INNERVATION OF THE TRICEPS BRACHII MUSCLE ULNAR NERVE TO THE TRICEPS BRACHII
}

\author{
Silva DLR, Barros MP, Freire TGS, Firmino Júnior L, Almeida Filho WRB, Correia Cadeira JSL, Silva NO
}

Correspondence to Diêgo Lucas Ramos e Silva Rua Prof. Virgilio Guedes, 1391 Ponta Grossa, 57014-220 Maceió, AL. Email: dyko.io@hotmail.com

The ulnar nerve is considered the thickest terminal branch of the medial cord in the brachial plexus and most authors does not mention the possibility of this nerve emitting branches to the arm. However, some studies reported that the ulnar nerve could supply the medial head of triceps brachii muscle. The main objective in this study was identifying the presence of ulnar nerve branches in triceps brachii muscle. Sixty upper limbs of adult Brazilian corpses of both sexes were used. The estimated age was between 25 and 80 years old. Every studied piece had the nerves and their branches quantified and measured with a manual mechanic caliper. The branches were photographed and had the data registered in individual files. Were found ulnar nerve branches for all the heads of triceps brachii muscle: 1 branch $(9,1 \%)$ to lateral head, 2 branches $(18,1 \%)$ to long head and 8 branches $(72,7 \%)$ to medial head. Thus, we can conclude that the contribution of ulnar nerve to triceps brachii muscle constitutes an important anatomical variation.

Key words: Ulnar nerve; Triceps brachii muscle; Innervation.

\section{INTRODUCTION}

The ulnar nerve is the terminal branch of the medial cord of the brachial plexus, receiving $\mathrm{C} 8$ fiber and T1, and sometimes C7 (Jamuna, 2011). It goes down to the medial arm region and passing to the medial epicondyle of the humerus, to the ulnar side of the forearm into the hand (Sallomi et al, 1998). The ulnar nerve innervates most muscles of the hand, some muscles of the forearm; especially the muscle flexor carpi and medial portion of the deep flexor digitorum (Sallomi et al, 1998). Just as the median nerve, it does not emit branches to the arm (Capitani and Beer, 2002). Some authors reported ulna innervation of the medial head of the triceps muscle on the posterior compartment of the arm, through the radial nerve associated with ulnar nerve branches (Pascual et al, 2013) or ulnar nerve branch innervating the triceps without existing communication with the radial nerve (Bekler et al, 2009).

Some authors emphasize the possibility of innervation of the triceps by surgical technique. But, if the individual naturally had communication between the radial nerve and the ulnar nerve or if he/she had direct branches from the ulnar nerve to the long head in any plexus injury, the ulnar nerve might as well fill the engine component to the triceps and enable the forearm extension (Pet et al, 2011; Flores, 2011).

Given the above, it is important to identify the possible presence of ulnar nerve branches in the triceps muscle and its clinical significance. Whereas this contribution is of utmost importance in trauma with nerve or muscle injury of the upper limb.

Submitted $26^{\text {th }}$ November 2016, revised on $7^{\text {th }}$ December 2016. Published online $12^{\text {th }}$ December 2016. To cite: Silva DLR, Barros MP, Freire TGS, Firmino Júnior L, Almeida Filho WRB, Correia Cadeira JSL, Silva NO. 2017. Ulnar nerve contribution in the innervation of the triceps brachii muscle ulnar nerve to the triceps brachii. Anatomy Journal of Africa. 6: 834 - 839. 


\section{MATERIALS AND METHODS}

This was an observational, descriptive, analytical and cross-sectional study. In conformity with the Brazilian Federal Law 8.501 of November 30, 1992, and after institutional approval, the upper limbs of 30 corpses of Brazilian adults, of both sexes were used, one female and 29 male, aged between 25 and 80 years old, fixed in $10 \%$ formaldehyde provided by Descriptive and Topographic anatomy laboratory of the State University of Health Sciences of Alagoas (UNCISAL). All upper limbs were articulated to the corpse.

Due to the great miscegenation in Brazil, the corpses were not classified according to the ethnicity. To perform the dissection, each of the corpses was initially placed in the supine position with arm in abduction on one of the Anatomy Laboratory tables. A longitudinal incision was made in the middle of the anterior elbow face following the arm until the acromion-clavicular joint (the skin was folded down). After delimiting the area to be studied, the tissues were dissected in a way that muscles, nerves and their branches could be entirely exposed to observation. All the cases studied had the nerves and their branches quantified, measured with manual mechanical caliper Metrica ${ }^{\circledR}$ as well as photographed with a digital camera Canon $®$.

For the analysis, from the acromion-clavicular joint, the arms were proportionally delimited in three segments: proximal, middle and distal. In each segment, the data for the following variables were recorded, the presence or absence of ulnar nerve branches to the triceps and in these cases the amount of such branches, as well as any communication between them and the radial nerve or other nerves brachial plexus.

The data for these variables were recorded in individual files. All data were recorded on an Excel spreadsheet for calculating the frequency distribution as well as calculate the average and standard error using the Bioestat 5.0 that analyzed data referring to the length of the ulnar nerve branches to the triceps muscle.

\section{RESULTS}

We selected 60 upper limbs, of these, 50 $(83.3 \%)$ there was no communication between the ulnar nerve and the radial nerve or other nerves of the brachial plexus. From the 10 members $(16.7 \%)$ correlated 9 (90\%) upper limbs contributions were observed from ulnar nerve branches to the triceps, 5 (55.5\%) with branches direct to this muscle, $3(33.3 \%)$ through communications between the ulnar and radial nerve and 1 (11.2\%) which showed both a direct branch to the triceps brachii muscle and communication with the radial nerve. Finally, 1 (10\%) limb presented communication between the nerve ulnar branch and musculocutaneous nerve.

There was no statistical correlation between the variables of gender, upper limb insertion side and the number of branches with the segments of the arm, in the analyzed sample. As to gender, of the 10 limbs, $9(90 \%)$ were males and $1(10 \%)$ female. In 6 out of the 9 males $(66.7 \%) 6(54.6 \%)$ ulnar branches of the middle segment were found, while in 3 limbs (33.3\%) were found 5 branches (45.4\%) in the distal segment, totalizing 11 branches found in this study. The branch length varied between $1.1 \mathrm{~cm}$ and $8,1 \mathrm{~cm}$, with an average of $3,72 \mathrm{~cm}$ and standard deviation of $2,57 \mathrm{~cm}$ (Table 1). In the female corpse branches were not found to the triceps muscle, however communication between the ulnar nerve and the radial nerve was observed in the proximal segment with $4 \mathrm{~cm}$ of length. 
Table 1 - Length of the ulnar nerve branches in the brachial triceps muscle

\begin{tabular}{|l|l|}
\hline Number of limbs & Branches length (cm) \\
\hline \multirow{4}{*}{1} & 7,1 \\
\cline { 2 - 2 } & 1,6 \\
\cline { 2 - 2 } & 1,1 \\
\hline 2 & 5,7 \\
\hline 3 & 1,1 \\
\hline \multirow{4}{*}{4} & 8,1 \\
\cline { 2 - 2 } & 2,8 \\
\hline & 2,0 \\
\hline \multirow{4}{*}{5} & 6,2 \\
\hline 6 & 1,9 \\
\hline
\end{tabular}

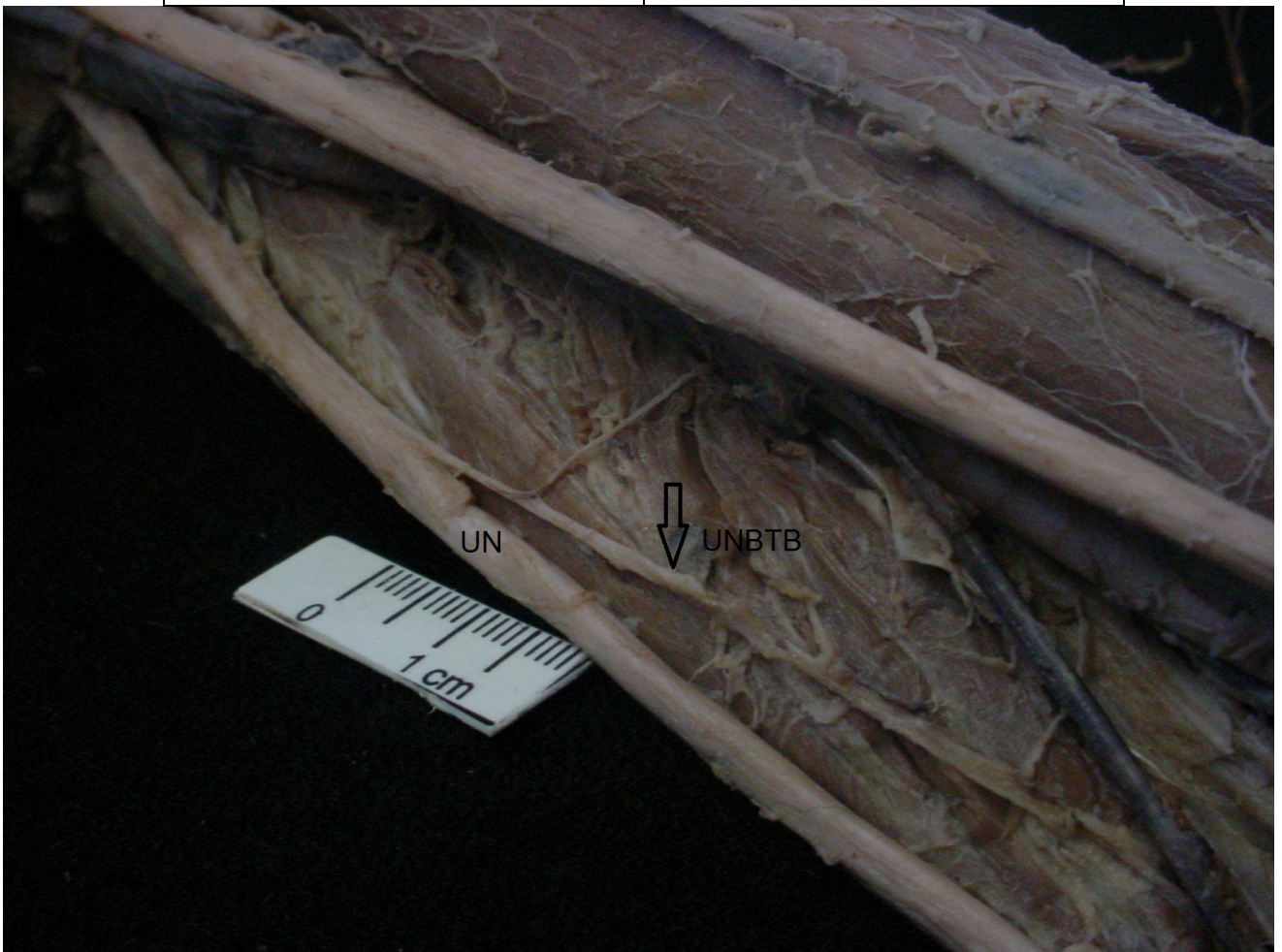

Fig. 1. Ulnar nerve branch to triceps brachialis muscle. UN = Ulnar Nerve; UNBTB = Ulnar Nerve Branch to Triceps Brachialis.

Regarding the innervation of the head of the triceps in all cases (100\%) innervated by the radial nerve, branches of the nerve ulnar were found to its three heads, with one branch $(9.1 \%)$ for the lateral head, 2 branches $(18.1 \%)$ for long head and $8(72.7 \%)$ to the medial head (Table 2). As to the distribution of the ulnar nerve, the presence of branches in the inferolateral portion of the triceps medial head portion was predominant (Figure 1). In the long head, the only branch distributed itself in its lateral portion. 
Table 2 - Distribution ulnar nerve to the lateral, long and medial heads of the triceps muscle in the arm segments.

\begin{tabular}{|c|c|c|c|c|c|c|}
\hline & \multicolumn{5}{|c|}{ Arm segment } & \\
\hline & Distal & & Middle & & Proximal & \\
\hline Triceps head & $\mathbf{N}$ & $\%$ & $\mathbf{N}$ & $\%$ & $\mathbf{N}$ & $\%$ \\
\hline Long & 0 & 0 & 2 & 18,1 & 0 & 0 \\
\hline Lateral & 0 & 0 & 1 & 9,1 & 0 & 0 \\
\hline Medial & 5 & 45,4 & 3 & 27,3 & 0 & 0 \\
\hline
\end{tabular}

$\mathrm{N}=$ Number of branches $\quad \%=$ Percentage

Regarding to the communication with the radial nerve was observed $1(25 \%)$ on the proximal segment and $3(75 \%)$ in the middle segment, with no communication in the distal segment. The length of these communications ranged between $4 \mathrm{~cm}$ to $7.2 \mathrm{~cm}$, with an average of $5,75 \mathrm{~cm}$ and standard deviation of $1,34 \mathrm{~cm}$ (Table 3). There was also a ulnar nerve communication with the musculocutaneous nerve in the middle segment with a length of $9.9 \mathrm{~cm}$.

Table 3 - Length of communications between the ulnar nerve and radial nerve

\begin{tabular}{|l|l|}
\hline UULL & $\begin{array}{l}\text { Length of communications } \\
(\mathrm{cm})\end{array}$ \\
\hline 1 & 4,0 \\
\hline 2 & 7,2 \\
\hline 3 & 6,2 \\
\hline 4 & 5,6 \\
\hline UULL = Upper Limbs (quantity) cm: Centímeters
\end{tabular}

DISCUSSION

In this study, most of the analyzed corpses were not observed ulnar nerve branches to the triceps brachii muscle. This condition was not observed in studies such as Loukas' et al (2013) which registered branch in $28 \%$ corpses the United States. Research conducted in Turkish population (Bekler et al, 2009) record percentage of occurrence of ulnar nerve contribution to the medial head of the triceps in $94.4 \%$ of the studied limbs.

Most of the ulnar nerve branches to the triceps muscle in the present study were located in the distal segment of the arm, variation was also observed in other studies, such as Loukas et al (2013) in which all branches studied by them in American corpses, the ulnar nerve branch to the triceps muscle appeared soon after the ulnar nerve pierce the medial intermuscular septum of the arm, ie in the distal segment of the arm according to McMin (2014).

The ulnar nerve presented communication with the radial nerve in 4 upper limbs in this study, this fact can be confirmed by some authors who observed in their studies branches of the ulnar nerve communicating with the radial nerve [Ip and Chang, 1968; Ajayi et al, 2012; Ozguner, 2010). Moreover, we observed in this work that in one of the upper limbs studied there was communication between ulnar nerve branches and musculocutaneous nerve in 
agreement with findings of Ajayi et al (2012) who reported such communication between these nerves. This finding suggests that the ulnar nerve can contribute indirectly to innervation of the muscles of the anterior compartment of the arm. However, more studies are needed to confirm this hypothesis.

As for the length, the ulnar nerve branches to the triceps brachii muscle were measured in this study ranging between $1.1 \mathrm{~cm}$ and $8,1 \mathrm{~cm}$, with an average of $3,72 \mathrm{~cm}$. In his study, Loukas et al (2013) noted that the length of the ulnar nerve branches varied between 1.2 to $4.5 \mathrm{~mm}$, with an average of $3.4 \mathrm{~mm}$. However, the measurement of the branches was performed using an image analysis computer-assisted system. This fact does not corroborate with this study regarding to the measurement of the length of the branches.

No studies were found that show the distribution of the branches of the ulnar nerve in the portions of the triceps, and also reports in the literature of the presence of branches of this nerve to the long and lateral heads of the triceps muscle have not been found, this has become a positive aspect of this study as it brings new information for future similar studies.

It is noteworthy that it was not possible to measure the diameter of the ulnar nerve branches to the triceps muscle in this study, considering that it had about $1 \mathrm{~mm}$ or less in diameter. Thus, we believe that this is due to the reduced number of studies on the branches of the ulnar nerve to the triceps muscle.

In conclusion, the ulnar nerve innervation contributes to the brachii triceps, however, this contribution refers to an anatomical variation. Therefore, it is crucial that the knowledge of the clinical and surgical aspects of the variation of innervation to the medial head of the triceps muscle is further investigated to know their real clinical significance. In addition, the branches of the ulnar nerve to the triceps muscle are small in diameter making it difficult to measure them.

\section{REFERENCES}

1. Ajayi NO, Lazarus L, Satyapal KS. 2012. Multiple Variations of the Branches of the Brachial Plexus with Bilateral Connections between Ulnar and Radial Nerves. Int J Morphol 30: 656660.

2. Bekler H, Wolfe VM, Rosenwasser, MP. 2009. A Cadaveric Study of Ulnar Nerve Innervation of the Medial Head of Triceps Brachii. Clin Orthop Relat Res 467: 235-238.

3. Capitani D, Beer S. 2002. Handlebar palsy - a compression syndrome of the deep terminal (motor) branch of the ulnar nerve in biking. J Neurol 249: 1441-1445.

4. Flores LP. 2011. Triceps Brachii Reinnervation in Primary Reconstruction of the Adult Brachial Plexus: Experience in 25 Cases. Acta Neurochir 153: 1999-2007.

5. Ip MC, Chang KSF. 1968. A study on the radial supply of the human brachialis muscle. Anat Rec 162: 363-372.

6. Jamuna, M. 2011. Clinically significant variations of the cords of the brachial plexus in relation to axillary artery. Int J Anat Var 4: 9-11.

7. Loukas M, Bellary SS, Yuzbasioglu N, Shoja MM, Tubbs RS, Spinner RJ. 2013. Ulnar Nerve Innervation of the Medial Head of the Triceps Brachii Muscle: A Cadaveric Study. Clin Anat 26: 1028-1030.

8. McMinn and Abrahams. 2014. Atlas colorido de anatomia humana. 7th ed. Rio de Janeiro: Elsevier, 400p.

9. Ozguner G, Desdicioglu K, Albay S. 2010. Connection between radial and ulnar nerves at high humeral level. . Int J Anat Var 3: 49-50.

10. Pascual A, Vazquez T, Marco F, Sanudo JR, Niedenfuhr MC. 2013. Ulnar Nerve Innervation of the Triceps Muscle: Real or Apparent? An Anatomic Study. Clin Orthop Relat Res 471: 18871893. 
11. Pet MA, Ray WZ, Yee A, Mackinnon SE. 2011. Nerve transfer to the tríceps after brachial plexus injury: report of four cases. J Hand Surg 36: 398-405.

12. Sallomi D, Janzen DL, Munk PL, Connell DG, Tirman PF. 1998. Muscle denervation patterns in upper limb nerve injuries: MR imaging findings and anatomic basis. AJR Am J Roentgenol 171: 779-784. 